\title{
HOW DO OUR MENTAL AND PERSONAL EXPERIENCE MEDIATE INTELLECTUAL EFFICIENCY? INTELLECTUAL COMPETENCIES AS PATTERNS OF INDIVIDUAL COGNITIVE PERFORMANCE
}

\begin{abstract}
This paper introduces the concept of intellectual competencies as patterns of individual cognitive performance, which manifest themselves while solving cognitive tasks and finding solutions. With the use of in-depth semi-structured interviews conducted while participants $(\mathrm{N}=15)$ solved cognitive tasks of two types, we revealed and informally described 7 intellectual competencies: 1) transformative efforts; 2) feedback receptiveness; 3 ) ability to compose conceptual gestalts based on past experiences; 4) simultaneous development of several alternative solutions; 5) insistence of cognitive attempts; 6) broad intellectual scope; 7) active information acquisition. It was shown that 4 of these competencies (feedback receptiveness, ability to compose conceptual gestalts based on past experiences, simultaneous development of several alternative solutions, broad intellectual scope) manifest themselves on the same level when solving different cognitive tasks. Intellectual competencies might be an alternative to existing approaches to intelligence studies as they integrate mental and personal experience, mediate actualization of one's mental resources, and determine the subject's intellectual efficiency. Refs 31 . Table 1 .

Keywords: intellectual competencies, individual cognitive behavior, alternative approaches to intelligence, intellectual efficiency.
\end{abstract}

\section{О.В. Щербакова}

\section{КАК НАШ КОГНИТИВНЫЙ И ЛИЧНОСТНЫЙ ОПЫТ ОПОСРЕДУЕТ ИНТЕЛЛЕКТУАЛЬНУЮ УСПЕШНОСТЬ? ИНТЕЛЛЕКТУАЛЬНЫЕ КОМПЕТЕНЦИИ КАК ПАТТЕРНЫ КОГНИТИВНОГО ПОВЕДЕНИЯ ЛИЧНОСТИ}

В статье вводится понятие интеллектуальных компетенций как паттернов когнитивного поведения личности, проявляющихся в процессе решения задач и опосредующих их успешное решение. Использование метода глубинного полуструктурированного интервью в процессе решения испытуемыми $(\mathrm{N}=15)$ двух различных когнитивных задач позволило нам выделить и содержательно описать 7 интеллектуальных компетенций: 1) преобразующая активность; 2) чувствительность к обратной связи; 3) умение формировать концептуальные гештальты на основе прошлого опыта; 4) параллельная разработка нескольких линий решения; 5) интеллектуальная настойчивость; 6) широта интеллектуального охвата ситуации; 7) активный сбор информации. Было показано, что 4 из этих компетенций (чувствительность к обратной связи, умение формировать концептуальные гештальты на основе прошлого опыта, параллельная разработка нескольких линий решения, широта интеллектуального охвата ситуации) проявляются на одном и том же уровне в процессе решения когнитивных задач различных типов. Интеллектуальные компетенции могут служить альтернативой традиционным подходам к изучению интеллекта, поскольку являются отражением когнитивного и личностного опыта субъекта и опосредуют его интеллектуальную успешность. Библиогр. 31 назв. Табл. 1.

Ключевые слова: интеллектуальные компетенции, когнитивное поведение личности, новые подходы к исследованию интеллекта, интеллектуальная продуктивность.

Shcherbakova O. V. - PhD, Associate Professor, St Petersburg State University, 7-9, Universitetskaya nab., St. Petersburg, 199034, Russian Federation; o.shcherbakova@spbu.ru

Щербакова Ольга Владимировна - кандидат психологических наук, доцент, Санкт-Петербургский государственный университет, Российская Федерация, 199034, Санкт-Петербург, Университетская наб., 7-9; o.shcherbakova@spbu.ru

(c) Санкт-Петербургский государственный университет, 2017 


\section{Introduction}

Soon after psychology of intelligence emerged as an independent research area, it appeared that many of the existing terms and tools were not as functional as they were supposed to be. Starting from C. Spearman [1] and L. Thurstone [2], the discussion on the nature of intelligence, its origins and proper definitions have been developed for decades [3-6]. In 2007, S. Legg and M. Hutter published a collection of definitions of intelligence [7], which showed the diversity of approaches but also weakness of psychological theory. The situation in psychological practice is also no better.

In 1930, L. Terman showed that traditional tests of psychometric IQ were not accurate predictors of real-life intellectual achievements [8]. Later he even concluded that 'intellect and achievement are far from perfectly correlated' [9, p. 352], however, the discussion about exactly what intelligence tests measured continued for much longer [10]. It ended up with D. McClelland's paper, where he suggested to switch from 'intelligence' testing to the testing of competencies as better predictors of real-life performance [11].

In 1990, R. Haier announced 'the end of intelligence research': back then, it seemed that advanced brain imaging technologies would provide major insights in the field [12]. But now, more than 25 years after those hopes were formulated, we are still far from any groundbreaking explanations on how our intelligence works. The only thing which has become more obvious is a burning need for fresh theoretical approaches and new measuring tools for intelligence.

One of the more advanced theoretical frameworks for intelligence studies is an ontological approach suggested by L. M. Vekker and later developed by M. A. Kholodnaya [13-16]. Within this ontological approach, intelligence is viewed as a sum of a person's mental experience $[14,15]$. We assume this definition of high importance since it highlights the subjective phenomenological aspects of intelligence, which are rarely taken into consideration in contemporary cognitive psychology. Meanwhile, this subjective side of the cognitive reality might provide us with some insights on how efficient thinking works. Also, the construct of mental experience does not separate 'pure' cognitive phenomenology from emotional and motivational context, which corresponds to some recent findings which show that there are numerous two-sided interactions between one's cognitive abilities and personal experience. Remarkably, these interactions directly influence the outcomes of one's intellectual efforts, which implies that moderate cognitive abilities can be enhanced significantly by the components of personality such as positive beliefs, values or productive habits, and vice versa, outstanding abilities can be suppressed by subjective projections, negative beliefs, dysfunctional self-concept, fears and nonproductive habits [17-19]. In the light of these findings, an ontological integration of cognitive processes and personality structures becomes even more obvious.

Consequently, many of the established terms which have been widely used in intelligence research — such as intellectual activity, intellectual operations, heuristics do not appear to be able to describe the complex reality of cognitive processes embedded into one's personal experience. Psychology of intelligence needs a major conceptual revision, and some new terms which consider the integrity of thinking processes, might be an essential part of such revision.

We suggest to describe one's intellectual activity as an individual cognitive behavior - a system of task-oriented cognitive operations and cognitive programs, which 
is habitually triggered by a problem situation and is reflective of a person's individual frame of mind [20]. Individual cognitive behavior 1) is aimed towards information acquisition and processing in order to solve a problem situation; 2) serves cognitive needs of a person; 3 ) is a behavioral manifestation of both intelligence and human personality; 4 ) is not a set of isolated cognitive operations but an integral system of those operations. As an integral system of cognitive and personal attributes, individual cognitive behavior includes one's cognitive habits, intellectual preferences, 'problem areas' in reasoning - all cognitive phenomenon which emerge on the grounds of biological basis of intelligence, but also bear the impressions of concrete personality's developmental history. We also hypothesize that there might be some patterns of an individual's cognitive behavior which are responsible for successful problem solving and include both processual and resultative characteristics of thinking.

Investigating individual cognitive behavior requires taking one's 'cognitive qualia' into consideration as they can throw some light on how does our intelligence work. This means that it is necessary to use qualitative research methodology in cognitive studies along with more traditional approaches.

Research in-depth interview remains one of the most unrivaled techniques for revealing and articulating one's first-person experience. Although it has been predominantly used for studying various emotional, motivational, social and health experiences, it is also promising when studying cognitive phenomenology [17, 19, 21-23]. In this exploratory study, we develop the technique of in-depth semi-structured interview in order to test the following hypotheses:

1) there are some patterns of individual cognitive behavior, which manifest themselves during cognitive tasks solving and underlie their successful transformation;

2) these patterns are persistent and reveal themselves in different cognitive tasks.

Since the study was conducted within a qualitative research paradigm, our main goal was to informally describe intellectual phenomenology, which underlies efficient cognitive behavior.

\section{Materials and methods}

\section{Participants}

Participants were 15 volunteers aged from 18 to 22, recruited through Saint Petersburg State University. All the participants had no visible signs of any somatic or mental disease.

\section{Method}

Participants were presented with two tasks ${ }^{1}$. These tasks were different from one another as regards content but both revealed patterns of a participant's individual cognitive behavior.

\section{Task 1. "Case solving"}

The first task was business-case based on real practice and offered by marketing research company Infowave [24]. The text of the case is presented below:

\footnotetext{
${ }^{1}$ The data were collected in collaboration with L. I. Khamatshina.
} 
Home air conditioners are not much-in-demand by the customers during the cold winter months. The company 'ClimatProf' faces significant decrease of home air conditioners sales during the winter period. What should the marketing policy of company be in order to increase air conditioner sales in winter?

The most obvious and stereotypical solution which comes to one's mind usually refers to a price reduction policy and special offers during winter period. However, this solution is not specific for air-conditioners sales (reducing prices and special offers can be applied to sales of any goods) and does not take into account some important and resourceful characteristics of this particular situation. The answers offered by Infowave company are more diverse and fit into one of the following strategies:

- challenging "Air conditioner means cooling system and nothing more" stereotype, which is common in most customers. Many air conditioners also have such options as heating, air purifying, humidifying and ionization. They also may function as ventilators in case of bad natural air access. Most potential customers are not aware of these additional options. Thus, if consider them when promoting air conditioners during winter time, there is a good chance to increase sales;

- canvassing of the customers who are already interested in buying an air conditioner but still have not done so during the last season. These customers can be offered a special "winter" reduced price and same day installations (since erection crews are less busy during off-season);

- targeting potential customers who are in process of a house renovation. Installing of an air conditioner usually means an aggressive intervention in interior design, which holds many potential customers back from buying it for home or office. Meanwhile, it is more likely that people who have just bought their new house or apartment, or doing some major renovation at their homes are ready to buy air conditioners. This category might be addressed through specialized media and renovation supplies.

We chose this case because it is rather ecological: it refers to every-day reality and describes a situation and object which are familiar to almost everyone. On one hand, this case does not require any special professional knowledge and can be solved within common sense framework. But on the other, it requires some divergent thinking skills and mental efforts. This case is short and thus, it's mental representation can be easily built and withhold in a recipient's mental space during the solving process. Another important characteristic of the case is that it does not look similar to any popular psychometric IQ test, which helps avoid anxiety state, common for most traditional psychological testing procedures.

\section{Task 2. "Real-life problem situation"}

In the second task, we asked participants to recall and retrospectively describe a problem situation they have ever faced during the last two years of their life. The main requirements were: 1 ) a situation was challenging and personally important for a participant; 2) it needed some intervention and could not be left unattended; 3) it was successfully overcome by a participant's own cognitive actions. It has to be noted, that we were interested not in crucial and stressful life events (which usually are of extremely high emotional importance and influence nearly all domains of one's experience [25]) but in 
problem situations (which are more local, involve limited domains of one's experience and require cognitive and instrumental reaction rather than deep emotional changes). Unlike Task 1, this problem was directly anchored to a participant's autobiographical narrative and could be referred to any domain of his/her personal experience. It is important, that we were not interested in a degree to which the narrated story corresponded to objective events which actually took place in the past. What we focused on more, was how a participant described the problem and a process of its solving as a part of a subjective mental representation. We also did not take into consideration the magnitude of a described problem situation - as soon as it was perceived and cognitively assessed by a participant as challenging one. All together, problem situations we were interested in met the characteristics of difficult life situations described by E. V. Bityutskaya [26].

This task was aimed to reveal any potential patterns of individual cognitive behavior, which spontaneously exhibit themselves when facing every-day challenges and help solve real life cognitive problems.

Consequently, we used two tasks, which were similar in terms of their ecological validity and both referred to real life problems. They both required cognitive efforts, although these efforts were to be undertaken either within more emotionally neutral context with preset conditions (as in Task 1) or within more emotionally involving but less predetermined situation (as in Task 2).

\section{Procedure}

Participants were tested individually. Each session lasted from 45 to 90 minutes and included two stages:

1) in-depth semi-structured interview during speaking-aloud case solving

2) in-depth semi-structured interview on stressful real-life situation.

At the first stage, the text of the Task 1 was presented to a participant in written form, along with the following instruction: "I am going to show you a small text describing a problem situation which happened in real life. Please, suggest some possible solutions for it and try to think aloud". After reading the text of the case, a participant started solving it. During this solving process, a participant could ask an experimenter some clarification questions, and the experimenter asked a participant a number of questions within a semistructured in-depth interview:

1) How did this idea start? What will it lead to?

2) Have you ever seen an air conditioner? Do you have any experience of using it?

3) How do you figure an air conditioner out for yourself?

4) Do you know how does it work?

5) When solving this problem, what position do you take? Do you see this situation from a seller's perspective or from a customer's one? Or do you view the situation from above?

6) Are there any other possible solutions?

7) Did you like this task? Was it interesting to solve it?

All the questions were aimed to clarify a participant's thinking process and make it more explicit. We tried to avoid any direct or indirect hinting since the main goal of our study was to describe qualitatively the natural process of thinking and to reveal possible 
patterns of efficient individual cognitive behavior, which mediate real-life problem solving. Question 1 was the most general one; it aimed to obtain more details concerning first-person perspective of reasoning process and a participant's mental experience related to the problem's mental representation. Questions $2-4$ allowed us to check the accuracy and completeness of a mental representation of a problem's key object and also reveal any subjective projections which might facilitate or distort the thinking process. Question 5 was aimed to test whether a participant was able to switch between different perspectives and, thus, broaden the scope of potential solutions. Question 6 was asked in order to test the degree to which a participant was able to critically view the results of his/her thinking and also whether the attempts to find a good solution were persistent or not. Question 7 was aimed to clarify possible interplay between cognitive processes and personality, and, if necessary, to release some emotional tension.

At the second stage, the Task 2 was followed by the instruction: "And now I will ask you to recall and describe a problem situation which you faced in the last two years of your life. This problem situation was new and you did not have any ready-made solution. It was also important for you and you had to deal intensively with this problem in a way which eventually led you to a successful solution". After presenting the instruction, the semistructured in-depth interview started. The guide for the interview included the following questions:

1) What was the main challenge of the situation that you are describing?

2) Why was that situation important to you?

3) What did you feel when it happened? What did you think about that situation?

4) What did you start doing?

5) How did you decide to act this way?

6) Was it hard to take those actions? What was the most difficult?

7) Did these actions lead to a success?

8) Which of your actions led to a successful problem solving? Were you fully aware of those actions?

9) Which of your personal traits were the most resourceful for that situation? Which ones were distracting?

10) How do you judge your actions now? Were they overall successful or not?

As in Task 1, all the questions were aimed to reveal any possible patterns of efficient individual cognitive behavior, which mediated the problem solving. Questions 1 and 2 helped to get a detailed phenomenological description of a problem's subjective meaning. Question 3 helped to verbalize emotional and cognitive aspects of the mental representation of the problem, while Question 4 focused on behavioral outcomes. Questions 5 and 6 aimed to reveal a subjective logic of how did the decision evolve, as well as the details of phenomenological experience corresponding to that evolvement. Questions 7 and 8 focused on retrospective metacognitive assessment of the undertaken actions, and Questions 9 and 10 aimed to summarize all the previously obtained information and to help delicately finish discussing emotionally-charged and cognitively challenging situation.

At both stages, all interviews were audio-recorded and then transcribed verbatim. All together, there were 30 protocols: 15 protocols of the interviews on cases solving and 15 - of the interviews on real-life problem solving. 


\section{Results}

All 30 protocols (15 interviews on case solving +15 interviews on real-life problem situation) were analyzed with the use of combination of meaning condensation technique [27] and systemic text condensation technique [28]. As a result of this qualitative analysis, 7 individually persistent patterns of intellectual performance which manifest themselves during cognitive tasks solving and help to find the correct answer were revealed. We called these patterns of intellectual performance intellectual competencies. The informal descriptions of the revealed competencies are presented below:

1) Transformative efforts

A person takes a problem as a situation to be transformed in according to his/her needs and wishes. Assumes that it is possible to solve a problem by his/her efforts. Considers him/herself an active subject of positive changes and embarks on steps for these changes. Undertaken actions are based on an implicit belief that his/her perspectives and values are of the highest priority. Tends not to be congruent with already existing context by fitting flexibly into it but to transform the reality in according with his or her own agenda and ideas, on the contrary. Views a current situation within a context of actual needs and motives. Does not wait until a problem will be solved due to natural progression of events or other people's actions.

2) Feedback receptiveness

Proactively seeks for a feedback from a situation itself or from other people and then takes it into account in course of his/her intellectual activity. Corrects thinking process in line with this feedback: develops more promising lines of reasoning and rejects those, which were recognized as wrong ones; narrows down or extends the mental space he or her is working with. Uses various strategies for problem solving. Seeks for information, which can prove or disprove the results of his/her thinking. Is very sensitive to any kind of prompting and hints, takes notice of them and immediately incorporates freshly acquired information into current cognitive activity. When solving a case, asks for feedback on whether suggested solutions were correct or incorrect and is curious about the correct solutions which were expected to be found.

3) Ability to compose conceptual gestalts based on past experiences

Shows consideration of the problem-relevant components of past experiences, conceptualizes them in relation to immediate goals and builds functional connections between these components and current task. Parallels current problem with past observations, factual knowledge, patterns of behavior stored in long-term memory. Is able to extrapolate elements of his/her past experiences to current cognitive task in no time. While reasoning, involves a wide range of autobiographical memories and abstract knowledge. Is able to switch quickly between different domains of past experiences, to assess the degree of their semantic relevance for the current problem and to choose those which match it the most.

4) Simultaneous development of several alternative solutions

A person is able to develop several alternative solutions simultaneously. Keeps within his/her mental space several possible outcomes - different but equally meeting the task's requirements, which helps to develop a number of possible scenarios. Points out the most preferred solution but develops it in line with elaborating some 'backup' options. 


\section{5) Insistence of cognitive attempts}

Once one has started solving a problem, follows through the line, shows persistence and overall intellectual sthenicity. On one hand, shows an expressed desire to find a solution for a problem in general and on the other, also to obtain a satisfactory result of elaborating a concrete intellectual strategy. Believes in a successful outcome of cognitive efforts even if the initial attempts yielded poor returns. Shows a reluctance to give up the elaboration of a chosen solution and keeps trying until a productive strategy of a problem solving is mapped out.

6) Broad intellectual scope

Knows how to distinguish various aspects of a matter, including unobvious ones, and how to build heterogeneous functional connections between these aspects. Flexibly switches between semantic contexts into which the problem-to-be-solved is incorporated.

7) Active information acquisition

Purposefully and actively looks for any information, which is necessary for building an accurate and full semantic representation of a current problem and also for making a decision on his/her next steps. Has a clear idea about exactly what kind of information is lacking for finding a solution and makes appropriate guesses on what kind of actions are needed to fill those information gaps. Embark on steps to search for necessary information with involvement of various resources (other people, technical equipment, his/her own past experiences).

At the next stage of the analysis, we used expert evaluation technique for testing the hypothesis about the persistency of intellectual competencies' manifestating within one's cognitive behavior. Two experts jointly evaluated 30 interview protocols (15 interviews on case solving +15 interviews on real-life problem situation). Their task was to assess whether and to what extend each of the 7 intellectual competencies was manifested by the participants during both case solving and real-life problem solving. The assessment was made in according to the 4-point grading scale suggested by M.Olekhnovitch for multi-purpose assessment of competencies. Within this scale, the manifestation of each competence can be ranked from score 4 (when the assessed competence is manifested on a very high, exceptional level and can be viewed as one's strong point) to score 1 (when one manifests a behavior which is completely opposite to the assessed competence, or anti-competence) (see Table 1).

Table 1. Grading scale for competencies assessment by M. Olekhnovitch

\begin{tabular}{|c|l|l|}
\hline Score & \multicolumn{1}{|c|}{ Name } & \multicolumn{1}{c|}{ Interpretation } \\
\hline 4 & Strong point & $\begin{array}{l}\text { A respondent showed a behavior, meeting all the required indicators (key } \\
\text { descriptions of a competence), several times. Also showed an appropriate } \\
\text { behavior going beyond the basic description. Any behavior, which might } \\
\text { be classified as opposite to the required indicators, is either missing or } \\
\text { minor }\end{array}$ \\
\hline 3 & Required standard & $\begin{array}{l}\text { A respondent showed a behavior meeting the required indicators, and } \\
\text { can be qualified as a competent person }\end{array}$ \\
\hline 2 & $\begin{array}{l}\text { Below required } \\
\text { standard }\end{array}$ & $\begin{array}{l}\text { A respondent had some success but also showed a behavior opposite to } \\
\text { the required indicators }\end{array}$ \\
\hline 1 & $\begin{array}{l}\text { Considerably below } \\
\text { required standard }\end{array}$ & $\begin{array}{l}\text { A respondent describes or shows a behavior, which is opposite to the } \\
\text { required indicators, several times }\end{array}$ \\
\hline
\end{tabular}


As a result of the evaluation, we had 105 (15 protocols ${ }^{\star} 7$ competencies) grades for case solving and 105 ( 15 protocols ${ }^{\star} 7$ competencies) grades for real-life problem solving, which were used for further statistical analysis. We used Wilkoxon T-test (pair-wise ranks comparison) for two related samples to compare the manifestation of intellectual competencies while case solving and real-life problem solving.

Statistically significant difference in the level of manifestation was shown for three competencies only: transformative efforts $(Z=-2,496 ; p=0,013)$, insistence of cognitive attempts $(Z=-2,913 ; p=0,004)$ and active information acquisition $(Z=-2,06 ; p=0,039)$. These three intellectual competencies were manifested on a higher level when solving real-life problem if compared to case solving. The rest of the intellectual competencies did not show any differences in the level of their manifestation while case solving and real-life problem solving.

\section{Discussion}

Qualitative analysis of the interview protocols allowed us to reveal 7 intellectual competencies, or relatively persistent patterns of individual cognitive behavior and describe one's cognitive identity. Intellectual competencies appear to be dynamic psychological characteristics, emerging at the junction of 'pure' cognitive functions and personality. They bear the impression of one's cognitive abilities (intelligence, memory, creativity, etc.) on one hand, and one's personal experience (attitudes towards various domains of knowledge, past successes and failures, fears and habits, etc.) on the other.

Although one might suggest that the concept of intellectual competencies can be reduced to already existing psychological terms (such as cognitive styles or coping strategies), we argue that they are separate phenomenology. Intellectual competencies, unlike cognitive styles, are not processual characteristics of the actions undertaken but actions themselves - moreover, they are efficient actions. The same is true of coping strategies: intellectual competencies describe not any actions aimed to solve a problem but successful actions with the emphasis on their cognitive components.

We chose the term 'competence' for naming this aspect of cognitive phenomenology because it has been widely used in management and assessment for describing efficient but non-specific actions which help achieving goals $[29,30]$. Although in these areas of human practice it has a very broad meaning and can refer to literally any behavior - as long as it leads to efficient problem solving - we narrow it down to manifestation of individual intellectual behavior which is aimed to cognitive tasks solving and reveals one's unique mental organization. From this perspective, the construct of intellectual competencies is to certain extent similar to the term 'cognitive competencies' which R. Boyatzis mentions in his work [31]. However, we tend to view intellectual competencies described in this paper as more concrete and particular behavioral manifestations of individual intelligence. Intellectual competencies are a kind of an 'interface' between one's intellectual potential and his/her real intellectual progress - in other words, they mediate actualization of a person's mental resources and determine his/her intellectual efficiency.

Apparently, the simultaneous manifestation of all 7 competencies within one's cognitive behavior is not very likely: it is rather a standard of an 'ideal mind' functioning than the description of one's real intellectual performance. This is why it was important 
to check the hypothesis about intra-individual persistence in the level of competencies manifestation while solving various cognitive tasks.

As it was described before, the statistical analysis showed that three out of seven intellectual competencies: transformative efforts, insistence of cognitive attempts and active information acquisition - manifest at a higher level while real-life problem solving if compared to case solving. This might be due to the fact that all these three competencies relate to different aspects of one's emotional involvement and motivation and, thus, underlie one's desire to find a solution. Also, it is very likely that the participants were much more motivated to solve their own real-life problem than a case offered by the experimenter. Consequently, these differences might be explained by the difference in tasks, although both case and real-life problem were rather ecological, they did not look like what traditional IQ tests do and triggered cognitive efforts. However, it is important to note, that even though there are some differences in competencies' level of manifestation due to the specificity of the cognitive tasks, the basic level of manifestation of each competence is necessary for thinking processes activation. Although, any intra-individual constellations of intellectual competencies as a persistent characteristic of one's individual cognitive behavior, as well as possible interplay between them, are matter of further studies.

\section{Limitations and conclusions}

The present study aimed to reveal any behaviorally observable and non-specific patterns of individual intellectual behavior, which manifest themselves while cognitive tasks solving and underlie their successful transformation. With the use of qualitative approach to studying cognitive phenomenology we described for the first time 7 persistent patterns which were named intellectual competencies: 1) transformative efforts; 2) feedback receptiveness; 3 ) ability to compose conceptual gestalts based on past experiences; 4) simultaneous development of several alternative solutions; 5) insistence of cognitive attempts; 6) broad intellectual scope; 7) active information acquisition. The concept of intellectual competencies describes separate cognitive phenomenology, which cannot be reduced to any of the existing psychological constructs. Intellectual competencies integrate one's cognitive abilities with one's personal experience and, thus, capture complex interaction between basic cognitive phenomenon and the way they find their expression within a context of concrete emotional, motivational and learning background. Particular mechanisms of such interaction is a matter of future research and we hope that a qualitative approach to studying cognitive phenomenology will help to unveil them.

Bringing in-depth interviews back to intelligence studies once again proves to be insightful and fruitful research tactics. Taking first-person mental experience into consideration is crucial for understanding how does the mind work and, also, for developing tools for intellectual efficiency enhancing. The construct of intellectual competencies might be a part of a more advanced theoretical framework for intelligence studies.

The main limitation of this study is a sample size (although, small samples are rather common and sometimes unavoidable for qualitative studies and descriptive designs). In the future, we plan to replicate this study with a larger — and more divert - sample, and also with the use of experimental or quasi-experimental research design. Besides that, it is needed to retest our hypotheses with various types of cognitive tasks. One of the directions of further research might be an attempt to answer a question about potential con- 
stellations of intra-individual intellectual competencies and their correlations with more traditional psychological characteristics (psychometric intelligence, conceptual abilities, etc.). Another important task is to investigate whether intellectual competencies can be purposefully developed. If this can be done, the new ways of enhancing intellectual efficiency may open up.

\section{Acknowledments}

The preparation of this manuscript was supported by the President of Russia grant № MK-7507.2016.6 "Psychological and psychophysiological bases of experts' intellectual productivity". We gratefully acknowledge the commentaries Mr. Russell Chan made on early versions of the manuscript of this paper.

\section{References}

1. Spearman C. General Intelligence", objectively determined and measured. The American Journal of Psychology, 1904, vol. 15, no. 2, pp. 201-292.

2. Thurstone L. L. Primary Mental Abilities. Chicago, University of Chicago Press, 1938.

3. McNemar Q. Lost: our intelligence? Why? American Psychologist, 1964, vol. 19, no. 12, pp. 871-882.

4. Neisser U. The concept of intelligence. Intelligence, 1979, vol. 3, no. 3, pp. 217-227.

5. Sternberg R. J., Detterman D. K. (Eds.). What is intelligence? Contemporary viewpoints on its nature and definition. Praeger Pub Text, 1986.

6. Neisser U., Bodoo G., Bouchard T. J., Jr., Boykin A. W., Brody N., Ceci S. J., Halpern D. F., Loehlin J.C., Perloff R., Sternberg R. J., Urbina S. Intelligence: knowns and unknowns. American psychologist, 1996, vol.51, no. 2, pp. 77-101.

7. Legg S., M. Hutter. A collection of definitions of intelligence. Frontiers in Artificial Intelligence and applications, 2007, vol.157, pp. 17-24.

8. Burks B. S., Jensen D. W., Terman L. M. The promise of youth. Ed. by L. M. Terman. Genetic studies of genius (Vol.3). Stanford, CA, Stanford University Press, 1930.

9. Terman L.M., Oden M. H. The gifted child grows up: Twenty-five years' follow-up of a superior group. Stanford University Press, 1947, vol. 4.

10. Boring E. G. Intelligence as the Tests Test It. Eds. J.J. Jenkins, D. G. Paterson. Studies in individual differences: The search for intelligence. East Norwalk, CT, US, Appleton-Century-Crofts, 1961, pp.210-214.

11. McClelland D.C. Testing for competence rather than for "intelligence". American psychologist, 1973, vol. 28, no. 1, pp. 1-14.

12. Haier R. J. The end of intelligence research. Intelligence, 1990, vol. 14, no. 4, pp.371-374.

13. Vekker L. M. Mind and Reality: A Unified Theory of the mental processes. Moscow, Meaning, 1998. (In Russian)

14. Kholodnaya M. A. Psychology of Intelligence: Research Paradoxes. $2^{\text {nd }}$ ed., revised and enlarged. St. Petersburg, Piter Publ., 2002. (In Russian)

15. Kholodnaya M. A. Psychology of Conceptual Thinking: From Conceptual Structures to Conceptual Abilities. Moscow, Institute of Psychology RAS Print, 2012. (In Russian)

16. Kholodnaya M. A., Volkova E. V. Conceptual Structures, Conceptual Abilities and Productivity of Cognitive Functioning: The Ontological Approach. Procedia-Social and Behavioral Sciences, 2016, vol.217, pp. 914-922.

17. Shcherbakova O.V. Cognitive mechanisms underlying the comprehension of comical texts. PhD thesis. Saint Petersburg, 2009. (In Russian)

18. Osorina M. V., Zhukova A. Yu. Cognitive habits as an indicator of intellectual self-regulation in students. Proceedings of Scientific Conference "Ananyevskiye Chteniya - 2011. Social Psychology and Life". Ed. by A. L. Sventsitskiy. St. Petersburg University Press, 2011, pp.315-317. (In Russian)

19. Shcherbakova O. V. Intellectual competencies within a structure of individual cognitive behavior. Abstract Book of the Fifth International Conference on Cognitive Science, 18-24.06.2012. In 2 vol. Vol.2. Kaliningrad, 2012, pp.725-726. (In Russian) 
20. Shcherbakova O.V. Understanding as a mental cross-language convertible translation (on comical texts material). Annals of Saint Petersburg State University, 2008, line 12, no. 4, pp. 215-225. (In Russian)

21. Shcherbakova O. V. Information-energy organization of some patterns of metacognitive regulation. Annals of Saint Petersburg State University, 2012, line 12, no. 3, pp. 103-114. (In Russian)

22. Osorina M.V., Chechik A. A. Studying everyday fantasizing in adults. Part 1: Approach and methods. Annals of Saint Petersburg State University, 2013, line 16, no. 3, pp. 25-34. (In Russian)

23. Osorina M. V., Chechik A.A. Studying everyday fantasizing in adults. Part 2: Results of testing methods of collecting and processing empirical data. Annals of Saint Petersburg State University, 2013, line 16, no. 4, pp. 14-29. (In Russian)

24. Manager, «DP» no. 224 (1566) from 01.12.2003. Available at: http://www.infowave.ru/publications/ cases/dp1566/ (accessed: 01.09.16).

25. Vasilyuk F.E. Psychology of Rueful Feelings: Analyzing of Coping With Critical Situations. Moscow, Moscow University Press, 1984. (In Russian)

26. Bityutskaya E. V. Difficult life situations: Criterion for cognitive evaluation. Psychological Science and Education, 2007, no. 4, pp. 87-93. (In Russian)

27. Kvale S. InterViews: an introduction to qualitative research interviewing. Thousand Oaks, CA, SAGE Publications, 2004.

28. Malterud K. Systematic text condensation: a strategy for qualitative analysis. Scandinavian journal of public health, 2012, vol. 40, no. 8, pp. 795-805.

29. Boyatzis R. E. The competent manager: A model for effective performance. John Wiley \& Sons, 1982.

30. Spencer L. M., Spencer P.S. M. Competence at Work: Models for superior performance. John Wiley \& Sons, 2008.

31. Boyatzis R. E. Competencies in the $21^{\text {st }}$ century. Journal of management development, 2008, vol. 27 , no. 1, pp. 5-12.

For citation: Shcherbakova O.V. How do our mental and personal experience mediate intellectual efficiency? Intellectual competencies as patterns of individual cognitive performance. Vestnik SPbSU. Psychology and Education, 2017, vol. 7, issue 1, pp. 43-54. DOI: 10.21638/11701/spbu16.2017.103.

Статья поступила в редакцию 14 сентября 2016 г.

Статья рекомендована в печать 16 марта 2017 г. 